\title{
Desain dan parameter hidrostatis kasko kapal fiberglass tipe pukat cincin 30 GT di galangan kapal CV Cipta Bahari Nusantara Minahasa Sulawesi Utara
}

\author{
Design of 30 GT fiberglass purse seiner at CV Cipta Bahari Nusantara Minahasa shipyard \\ North Sulawesi
}

\author{
LINDA KANTU*, PATRICE N.I. KALANGI dan JANNY F. POLII \\ Program Studi Pemanfaatan Sumberdaya Perikanan, Fakultas Perikanan dan Ilmu Kelautan, \\ Universitas Sam Ratulangi, Manado 95115
}

\begin{abstract}
Purse seiners made of fiberglass are increasingly used. Information about the characteristics of such boats operated in North Sulawesi waters is, however, scarcely available. This study was done at CV Cipta Bahari Nusantara Minahasa shipyards to re-draw the hull form of 30 GT fiberglass purse seiner and to obtain its hydrostatic characteristics using Free!Ship application program. The results indicate that this boat tends to be higher and longer in shape comparing to wooden purse seiners, and the hydrostatic parameters change with its draft. Displacement, Aw, LCF and fineness coefficient increase with draft, while LCB, KMl and KMt decrease with draft.
\end{abstract}

Keywords: design, hydrostatics, fiberglass, purse seiner, Free!Ship, North Sulawesi

\begin{abstract}
ABSTRAK
Kapal pukat cincin yang terbuat dari fiberglass semakin banyak digunakan. Akan tetapi informasi karakteristik kapal demikian yang dioperasikan di perairan Sulawesi Utara belum banyak tersedia. Penelitian ini dilakukan di galangan kapal CV Cipta Bahari Nusantara Minahasa untuk menggambarkan kembali bentuk kasko kapal pukat cincin 30 GT dan untuk mendapatkan karakteristik hidrostatis kapal tersebut dengan menggunakan program aplikasi Free!Ship. Hasil penelitian menunjukkan bahwa kapal ini cenderung memiliki bentuk lebih tinggi dan panjang dibanding kapal pukat cincin kayu, dan parameter hidrostatis berubah seiring bertambah draft kapal. Displacement, Aw, LCF dan koefisien bentuk akan semakin besar dengan bertambah draft, sedangkan LCB, KMl dan KMt akan menurun seiring bertambah draft kapal.
\end{abstract}

Kata-kata kunci: desain, hidrostatik, fiberglass, kapal pukat cincin, Free!Ship, Sulawesi Utara

\section{PENDAHULUAN}

Kapal ikan merupakan salah satu faktor yang penting di antara komponen unit penangkapan lainnya, dan umumnya merupakan modal terbesar yang ditanamkan pada usaha penangkapan ikan. Oleh karena itu perencanaan dan konstruksi kapal ikan yang baik merupakan langkah penting dalam memulai usaha penangkapan ikan (Nomura dan Yamazaki, 1977).

\footnotetext{
*Penulis untuk penyuratan; email: kantulinda@yahoo.com
}

Ayodhyoa (1972) menyatakan bahwa kapal dapat berbentuk langsing atau gemuk, tergantung pada besaran koefisien bentuk kapal seperti koefisien balok $(\mathrm{Cb})$, koefisien penampang tengah, $(\mathrm{Cm})$, koefisien garis air $(\mathrm{Cw})$ dan koefisien prismatik (Cp). Hubungan antara $\mathrm{Cb}, \mathrm{Cp}$ dan $\mathrm{Cm}$ adalah $\mathrm{Cb}=\mathrm{Cp} \times \mathrm{Cm}$ dan berdasarkan besarnya $\mathrm{Cb}<\mathrm{Cp}<\mathrm{Cm}$.

Untuk keselamatan dan efisiensi dari pengoperasian kapal, sangat penting pihak desainer kapal dan operator untuk mengetahui karakteristik kapal terutama karakteristik bagian badan kapal yang berada di bawah permukaan air. Karakteristik dari lambung kapal dihitung untuk beberapa 
kondisi garis air termasuk seluruh kondisi muatan yang mungkin dialami oleh sebuah kapal. Garis air diasumsikan sejajar dengan garis dasar kapal (Masengi, 2011).

Material kasko kapal dapat berupa kayu, besi atau fiberglass. Dilihat dari konstruksi material dan pembuatannya kapal fiberglass memiliki keunggulan lebih banyak dibandingkan dengan kapal kayu maupun kapal besi. Keunggulankeunggulan ini menjadi semakin baik apabila desain kapal tersebut juga baik. Sayang sekali informasi mengenai desain kasko kapal fiberglass khususnya kapal tipe pukat cincin di daerah Sulawesi Utara belum banyak terdokumentasikan. Oleh sebab itu penelitian tentang desain kapal ikan fiberglass, tipe pukat cincin dilakukan di galangan kapal CV Cipta Bahari Nusantara Minahasa. Penelitian ini bertujuan untuk menggambar kembali bentuk kasko kapal pukat cincin 30 GT di galangan kapal CV Cipta Bahari Nusantara Minahasa dan untuk mendapatkan karakteristik hidrostatis kapal tersebut dengan program aplikasi Free!Ship.

\section{METODE PENELITIAN}

\section{Pengumpulan data}

Objek dari penelitian ini adalah kapal fiberglass tipe pukat cincin 30 GT yang ada di galangan kapal CV Cipta Bahari Nusantara Minahasa di Tanawangko, Sulawesi Utara. Data kapal yang dikumpulkan meliputi ukuran utama dan ukuran kasko kapal (bagian luar) pada sepuluh stasiun di sepanjang badan kapal. Peralatan yang digunakan antara lain benang, alat tulis-menulis, kamera dan meteran $(5,10$, dan $50 \mathrm{~m})$.

\section{Penggambaran lambung kapal}

Data pengukuran kapal di lapangan dimasukkan dalam program Excel Microsoft Office 2007 dan dikoreksi untuk mendapatkan data yang diperlukan. Berdasarkan data ini, bentuk kasko kapal digambarkan kembali dengan menggunakan program aplikasi Free!Ship. Aplikasi ini merupakan program pemodelan yang secara khusus ditujukan untuk desain kapal (Engeland, 2006). Hasil penggambaran ditampilkan dalam bentuk body-plane, buttock-line, dan waterline. Berdasarkan gambar yang dibuat, parameter hidrostatis didapatkan dengan menggunakan perhitungan otomatis dari Free!Ship.

\section{HASIL DAN PEMBAHASAN}

\section{Hasil penggambaran kembali kasko kapal}

Kapal pukat cincin yang terbuat dari fiberglass ini memiliki beberapa crease yang tidak dimiliki oleh kapal pukat cincin yang terbuat dari kayu pada umumnya. Oleh sebab itu, penggambaran dan hasil penggambaran kapal fiberglass ini tidak sama dengan kapal pukat cincin kayu. Hasil penggambaran kembali bentuk kasko kapal ditampilkan pada Gbr. 1. Gambar tersebut berupa linesplan kapal yang telah sesuai dengan data pengukuran dan foto-foto kapal tersebut. Adapun gambar linesplan tersebut berupa profil view, plan view dan body plan. Profil view merupakan gambar tampak samping kapal (panel atas), plan view merupakan gambar tampak atas kapal (panel bawah), sedangkan untuk body plan merupakan gambar tampak dari haluan dan buritan (panel tengah).

\section{Perbandingan dimensi utama kapal}

Dimensi utama dan nilai perbandingan antar dimensi utama kapal merupakan faktor penting dalam perencanaan pembangunan suatu kapal ikan, yang dapat mempengaruhi performa kapal. Kapal pukat cincin fiberglass ini memiliki ukuran panjang 20,40 m, lebar 4,31 m, dan dalam 2,90 m.

Nilai perbandingan antar ukuran utama kapal adalah L/B 4,7, L/D 7,03, dan B/D 1,48. Nilai ini kecuali $\mathrm{L} / \mathrm{B}$ berada di bawah nilai yang dilaporkan Suzuki (1978) untuk kapal pukat cincin yang panjangnya kurang dari $22 \mathrm{~m}$ yaitu L/B 4,30, L/D 10,00 , dan $\mathrm{B} / \mathrm{D} 2,15$. Jika dibandingkan dengan nilai perbandingan kapal pukat cincin berbahan kayu yang berpangkalan di Bitung dengan L/B 4,32, L/D 11,47, dan B/D 2,62 (Saiye, 1989), kapal fiberglass ini memiliki L/B lebih besar tetapi L/D dan B/D yang lebih kecil. Nilai L/B yang besar mengartikan bahwa kapal ini memiliki bentuk yang kurang lebar atau lebih panjang, sedangkan nilai L/D dan B/D yang lebih kecil mengindikasikan bahwa kapal ini memiliki bentuk yang lebih tinggi.

\section{Kurva hidrostatis kapal}

Kurva-kurva hidrostatis kapal pukat cincin fiberglass ini disajikan pada Gbr. 2 dan 3. Suatu gambar hidrostatis dapat terdiri dari beberapa kurva. Dalam hal demikian gambar tersebut dapat memiliki beberapa sumbu $\mathrm{X}$ yang sesuai dengan skala satuan dan parameter yang digunakan, seperti pada Gbr. 2. 

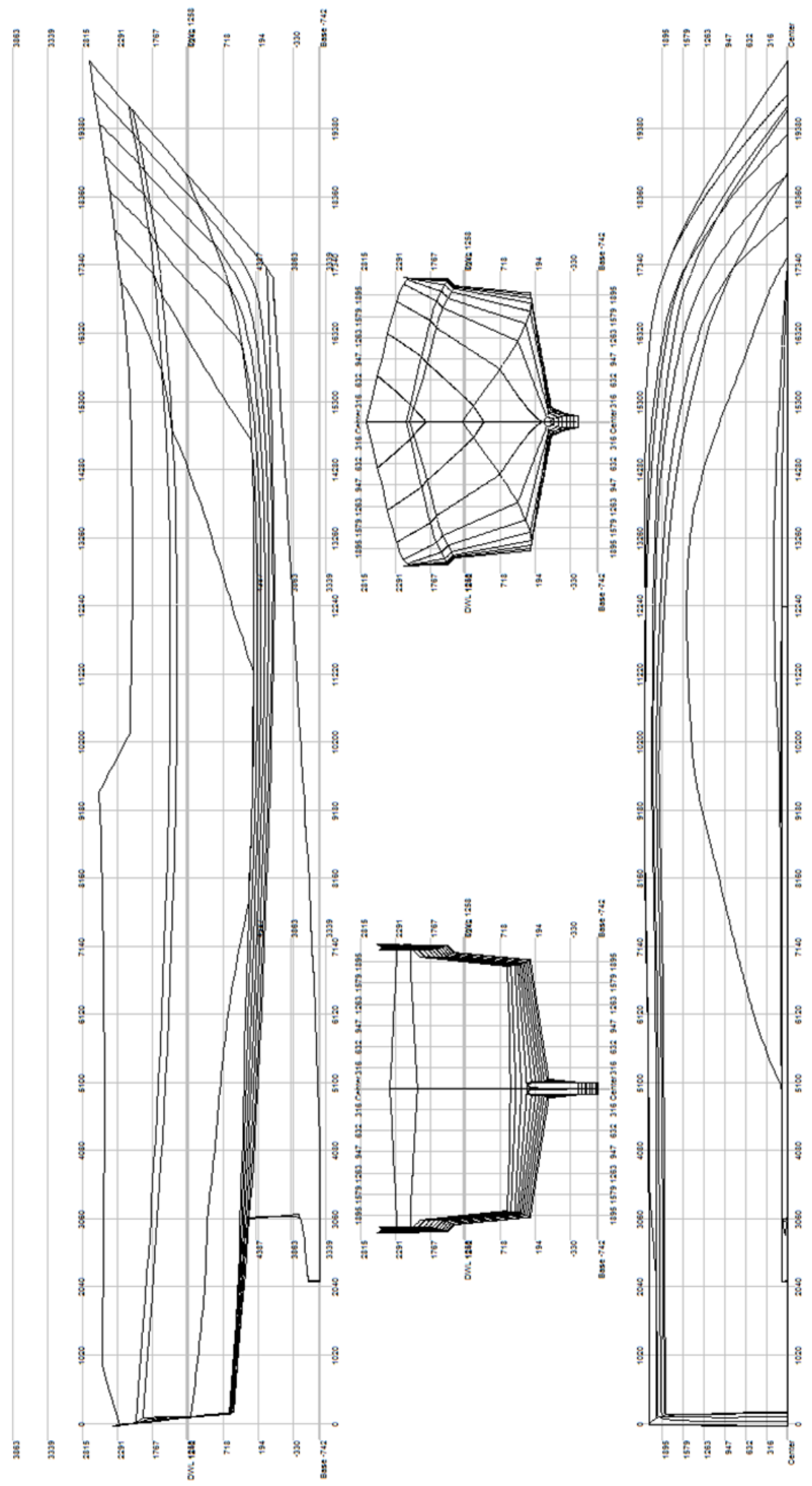

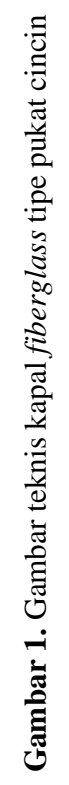




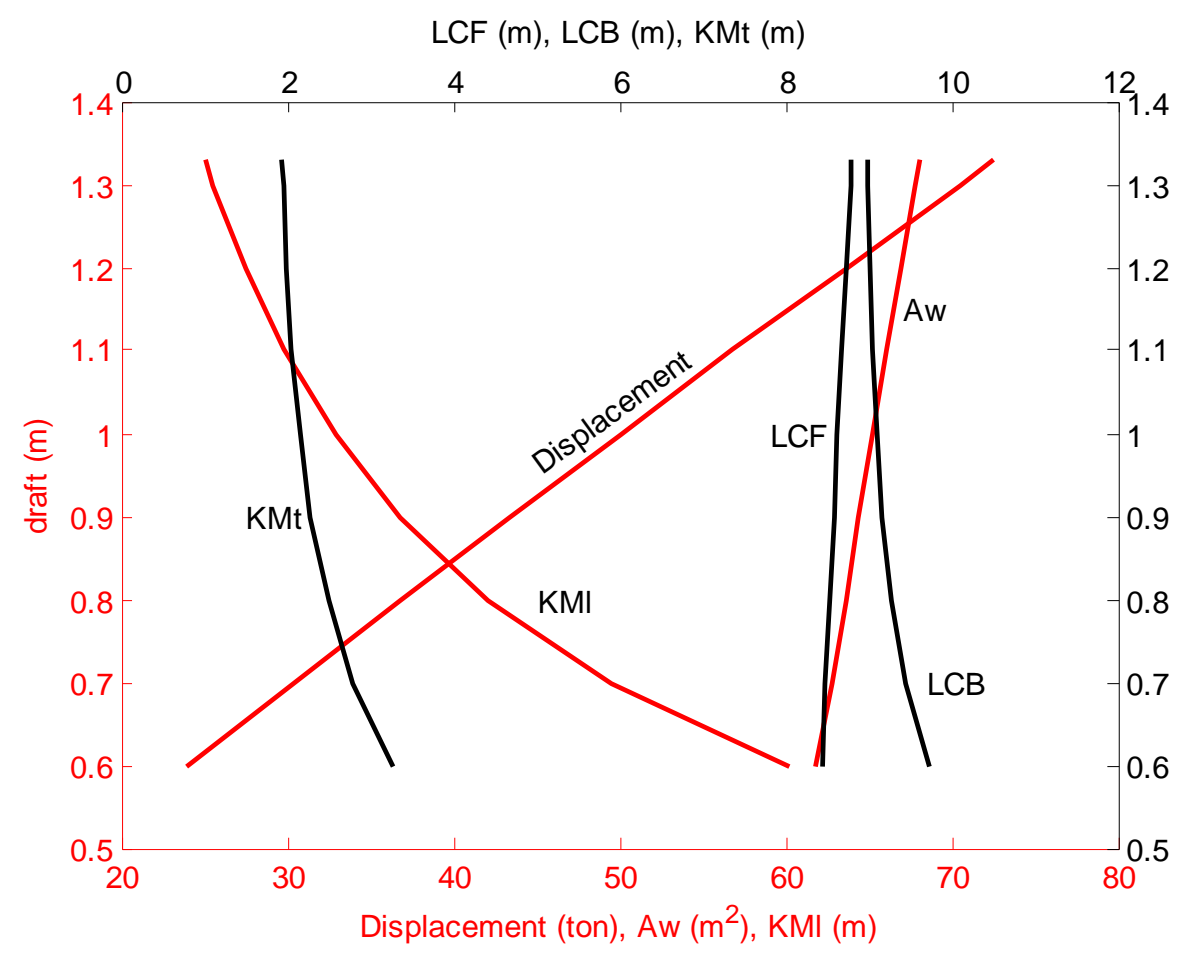

Gambar 2. Kurva hidrostatis: Displacement, KMl (Keel to longitudinal Metacenter height). KMt (Keel to transverse Metacenter height), Aw (Waterplane Area), LCB (Longitudinal Center of Bouyancy), LCF (Waterplane Center of Floatation)

\section{Displacement}

Nilai displacement pada draft $0,60-1,33 \mathrm{~m}$ berkisar antara 23,97 dan 72,57 ton. Displacement kapal akan semakin bertambah secara linear pada saat draft kapal semakin naik. Berat kapal fiberglass ini pada kondisi draft maksimal adalah sebesar 72,57 ton.

\section{Waterplane area}

Pada Gbr. 2 terlihat bahwa pada tiap kenaikan draft, nilai Aw makin bertambah. Luas area kapal pada kondisi draft kosong $(0,60 \mathrm{~m})$ sebesar 61,75 $\mathrm{m}^{2}$ sedangkan pada kondisi draft maksimal $(1,33$ m) sebesar $68.06 \mathrm{~m}^{2}$. Dengan demikian selisih luas Aw dari draft 0,60 dan 1,33 adalah sebesar 6.31 $\mathrm{m}^{2}$.

\section{Longitudinal center of buoyancy}

Jarak titik tekan buoyancy semakin menurun dengan bertambahnya draft. Pada draft 0,60 dan $1,33 \mathrm{~m}$ nilai LCB secara berturut-turut adalah 9,72 dan $8,98 \mathrm{~m}$. Hal ini menunjukkan bahwa semakin tinggi draft kapal maka LCB kapal akan semakin mengarah ke buritan kapal, hal ini mungkin disebabkan oleh volume kapal di bagian buritan semakin bertambah.

\section{Longitudinal center of floatation}

Jarak titik pusat floatation semakin bertambah dengan bertambahnya draft. Pada draft 0,60 dan $1,33 \mathrm{~m}$ nilai LCF secara berturut-turut adalah 8,43 dan $8,8 \mathrm{~m}$. Hal ini menunjukkan bahwa semakin tinggi draft kapal maka LCF kapal akan semakin mengarah ke haluan kapal. Hal ini mungkin disebabkan oleh pengaruh LWL yang semakin panjang. Titik LCF berada di arah buritan dari titik LCB. Hal ini membuat titik LCF dan LCB semakin berimpit dengan dengan bertambahnya draft kapal.

\section{Keel to longitudinal metacenter height}

KMl merupakan tinggi metacenter memanjang terhadap lunas kapal untuk tiap-tiap sarat kapal. Nilai KMl pada draft 0.60 dan 1,33 m masingmasing adalah 60,25 dan 25,02 m. KMl kapal semakin menurun seiring bertambahnya draft kapal. Hal ini dapat mengartikan bahwa semakin tinggi draft kapal maka anggukan kapal akan semakin sedikit. Pada kurva hidrostatis, terlihat 
bahwa semakin tinggi draft maka kurva KMl akan bergerak turun ke kiri secara tidak linear.

\section{Keel to transverse metacenter height}

KMt merupakan tinggi metacenter melintang terhadap lunas kapal untuk tiap-tiap sarat kapal. Nilai KMt akan menurun seiring bertambahnya draft kapal, pada draft 0,60 dan 1,33 m masingmasing adalah 3,28 dan 1,94 m. Hal ini dapat menjelaskan bahwa semakin bertambah draft kapal maka olengan kapal semakin mengecil.

\section{Koefisien bentuk}

Koefisien bentuk kapal ditampilkan pada Gbr. 3. Gambar tersebut memperlihatkan bahwa $\mathrm{Cb}$ lebih kecil daripada $\mathrm{Cp}$, dan $\mathrm{Cp}$ lebih kecil daripada $\mathrm{Cm}$. Hal ini sesuai dengan yang dinyatakan oleh Ayodhyoa (1972). Nilai standar koefisien bentuk kapal yang menjadi patokan sebagaimana yang dikemukakan oleh Suzuki (1978), yaitu Cb: 0,570,68, Cp: 0,67-0,75, Cm: 0,91-0,95; Cw: 0,760,94 .

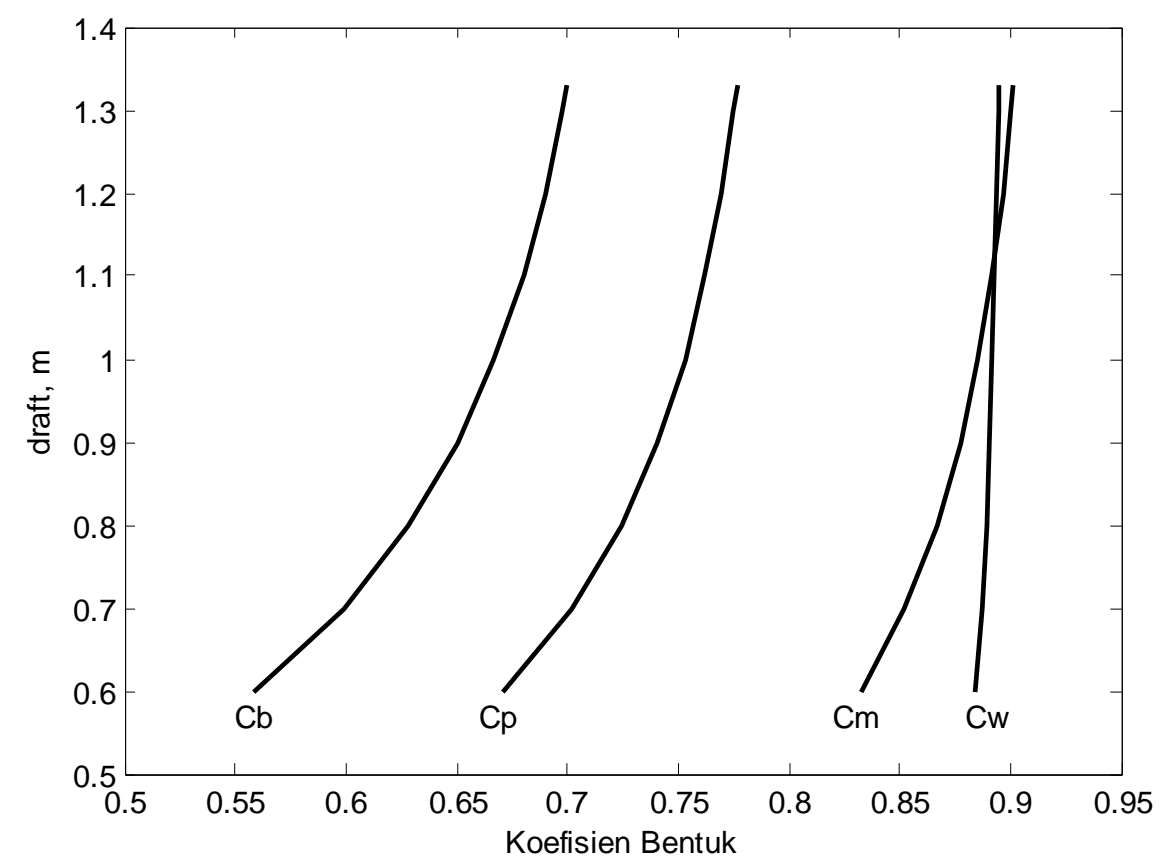

Gambar 3. Koefisien balok $(\mathrm{Cb})$, koefisien prismatik $(\mathrm{Cp})$, koefisien penampang tengah $(\mathrm{Cm})$, koefisien garis air $(\mathrm{Cw})$

\section{Koefisien balok}

Koefisien balok $(\mathrm{Cb})$ adalah nilai perbandingan antara volume badan kapal yang berada dibawah permukaan air dengan volume balok yang membatasinya atau yang dibentuk oleh panjang, lebar dan tinggi balok. Nilai $\mathrm{Cb}$ kapal pada draft 0,60-1,33 yaitu antara 0,56 dan 0,70 , yang berarti bahwa 55$70 \%$ dari volume kapal adalah dalam bentuk balok. Dengan demikian maka badan kapal ini cenderung berbentuk gemuk. Hal ini dapat menguntungkan pada stabilitas kapal namun pada saat kapal dijalankan kapal ini mendapatkan tahanan yang lebih besar dari fluida cair. Dapat dilihat dalam kurva koefisien bentuk kapal. Jika dibandingkan dengan nilai standar Suzuki (1978), maka kisaran $\mathrm{Cb}$ kapal ini lebih luas. Hal ini mungkin akibat dari luasnya kisaran draft yang digunakan.

\section{Koefisien penampang tengah}

$\mathrm{Cm}$ adalah nilai perbandingan antara luasan penampang tengah yang berada di bawah permukaan air dengan luas penampang empat persegi panjang yang membatasinya atau yang dibentuk oleh lebar dan tinggi empat persegi panjang. Nilai Cm kapal ini berkisar antara 0,83 dan 0,90 untuk draft $0,60-1,33 \mathrm{~m}$. Hal ini yang berarti bahwa luas penampang tengah kapal adalah berkisar antara 83-90 \% dari luas penampang melintang kapal dalam bentuk empat persegi. Dengan demikian maka penampang tengah kapal ini mendekati 
bentuk empat persegi, sehingga stabilitas kapal ini dapat semakin baik. Akan tetapi, Cm kapal ini lebih kecil dibandingkan $\mathrm{Cm}$ yang diberikan oleh Suzuki yakni 0,91-0,95

\section{Koefisien garis air}

Koefisien garis air adalah nilai perbandingan antara luasan penampang garis air dengan luas penampang empat persegi panjang yang membatasinya atau yang dibentuk oleh panjang dan lebar empat persegi panjang. Nilai $\mathrm{Cw}$ untuk kapal ini berkisar antara 0,88 dan 0,90 untuk draft 0,60 $1,33 \mathrm{~m}$. Hal ini berarti bahwa luas bidang yang dibentuk oleh garis air adalah $88-90 \%$ dari luas bidang air dalam bentuk empat persegi. Dengan demikian dapat dikatakan bahwa luas bidang yang dibentuk oleh garis air pada kapal ini mendekati bentuk empat persegi, sehingga dapat menguntungkan pada stabilitas kapal. Cw kapal ini berada pada kisaran bagian atas dari $\mathrm{Cw}$ yang diberikan oleh Suzuki yakni 0,76-0,94.

\section{Koefisien prismatik}

Koefisien prismatik (Cp) adalah perbandingan antara nilai volume displacement kapal dengan volume yang dibentuk oleh luas area penampang melintang tengah kapal (Am) dan panjang kapal pada garis air tertentu (Lwl). Nilai Cp kapal ini berkisar antara $0,67-0,78$ untuk draft $0.60-1.33 \mathrm{~m}$. Hal ini berarti bahwa volume displacement adalah $67-78 \%$ dari volume kapal yang dibentuk oleh luas area penampang melintang tengah kapal dan panjang kapal pada LWL tertentu. Nilai Cp yang semakin besar menunjukkan bahwa penampang melintang kapal baik ke arah haluan maupun ke arah buritan akan makin sama dengan penampang melintang tengah kapal. Kapal ini memiliki kecenderungan penampang melintang pada bagian buritan sama dengan penampang melintang tengah kapal. Sedangkan pada bagian haluan kapal cende- rung berbentuk lancip. $\mathrm{Cp}$ kapal ini berada pada kisaran dari $\mathrm{Cp}$ yang diberikan oleh Suzuki sebesar $0,67-0,75$.

\section{KESIMPULAN}

1. Desain kasko kapal fiberglass tipe pukat cincin 30 GT di galangan kapal CV Cipta Bahari Nusantara Minahasa telah digambar kembali menggunakan Software Free!Ship dengan hasil yang baik.

2. Kapal ini cenderung tinggi dan panjang tetapi dapat cukup stabil karena koefisien bentuk yang relatif besar.

3. Parameter hidrostatis berubah dengan perubahan draft. Displacement, Aw, LCF, dan koefisien bentuk bertambah dengan pertambahan draft. Sedangkan LCB, KMl, dan KMt menurun dengan pertambahan draft.

4. Titik-titik LCB dan LCF semakin berdekatan dengan bertambahnya draft.

\section{DAFTAR PUSTAKA}

Ayodhyoa, A.U. 1972. Fishing Boat. Correspondence Course Center. IPB Bogor.

Engeland, M.V. 2006. Free!Ship Manual. http://sourceforge. net.projects/free!ship.

Masengi, M. 2011. Kajian kurva hidrostatis kapal pukat cincin (small purse seiner) pada beberapa tempat di sulawesi utara. Skripsi. Fakultas Perikanan dan Ilmu Kelautan, Universitas Sam Ratulangi, Manado.

Nomura, M. dan T. Yamazaki. 1977. Fishing Techniques I. Japan International Corporation Agency, Tokyo.

Saiye, Z. 1995. Studi tentang beberapa karakteristik dinamis kapal pukat cincin di kecamatan bitung tengah kotamadya bitung. Skripsi. Pemanfaatan Sumberdaya Perikanan, Fakultas Perikanan, Universitas Sam Ratulangi, Manado.

Suzuki, O. 1978. Handbook for fisheries scientists and technologists. Training Dept. SEAFDEC. Thailand. 